\title{
The Impact of Educational Infographic on Students' Interaction and Perception in Jordanian Higher Education: Experimental Study
}

\author{
Derar Alqudah
}

PhD candidate, Multimedia University, Malaysia, qudahderar_86@yahoo.com

\author{
Azman Bin Bidin \\ Dr., Lecturer, Multimedia University, Malaysia,azman.bidin@mmu.edu.my
}

\section{Mohd Azizul Hakim Bin Md Hussin}

Lecturer, Multimedia University, Malaysia,azizul.hakim@mmu.edu.my

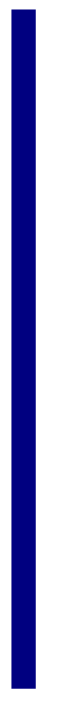

\begin{abstract}
This study aims to evaluate the effect of employing infographics in higher education, specifically with regard to students' interactions and their perception of the meaning of transferred information. This evaluation was presented through lectures at Applied Sciences Private University in Jordan and two other selected colleges (one scientific and the other humanistic) to compare the two variables applied in this study. To achieve this object infographic materials were developed by researcher and guided by (ASSURE) instructional model to present the lectures to the two experimental groups by infographic method through two selected courses from Information Technology College and Business College. Meanwhile, two control groups were taking the same courses in deferent class by conventional method. In addition, the total of participants was (138 students) and that includes all students of the experimental and control groups. Furthermore, a post-test questionnaire was involved to experimental groups to measure their interaction and perception after presenting lectures by infographic materials. The findings of this study show that infographics have a positive and strong impact on students' interaction and perception. Furthermore, a comparison shows that the students of the scientific and humanistic colleges had different effect of interaction. However, infographics have a similar effect on perception in both colleges.
\end{abstract}

Keywords: infographic, ASSURE model, interaction, perception, scientific, humanistic

\section{INTRODUCTION}

Infographics have become one of the most popular visual design fields on account of two core desirable outcomes: engagement of components and memorability of elements. These outcomes characterize the whole design and interpret the desirability of

Citation: Alqudah, D., Bidin, A., \& Md Hussin, M. A. H. (2019). The Impact of Educational Infographic on Students' Interaction and Perception in Jordanian Higher Education: Experimental Study. International Journal of Instruction, 12(4), 669-688. https://doi.org/10.29333/iji.2019.12443a 
infographics by arranging complex data in a visually appealing and memorable form that aims to attract the reader's attention (Lin, at al, 2000). The term "infographic" is derived from the words 'information graphic,' which refers to pictures that merge graphic design with a collection of data to convey messages to the audience in brevity and establish good communication with them (Smiciklas, 2012). So, Infographics can be described as a provider of information in a desirable way as well as to introduce tremendous amount of information with effectively and efficiency and this happen by reducing the contents of whole information or data. The main aspect that distinguishes infographics from other visual media, such as photographs, is the specific practical manner that employs maps, symbols, videos, and technical documents to deliver information in a clear and simple manner (Babu, 2015).

Information graphics can also convert complex data to an arranged and ornamented design, which can be modified in accordance with the preferences of users (Harrison \& Reinecke, 2015). Furthermore, infographics can be supported by relevant text to enhance the perception of audiences(Bladon \& Poulin, 2014). Infographics have been used widely through several areas one of these areas is education, which can be facilitated through infographic design for the benefit of students. In recent years, modern technology has shown the trend of becoming the basis of design education in three ways: by using networks, traditional methods, and infographics. The aesthetic side of infographics is crucial to introduce the components of design through interaction in a joyful manner. This task necessitates general knowledge from the designer instead of specialist knowledge on subjects (Gao \& Ming, 2014). Furthermore, the materials that are utilized in the educational process vary, including multimedia elements such as images, audio files and videos. In this way, the information can be transmitted to the students in an alternative way different from the traditional classroom and can be gained through visual means, which is one of the most significant forms of presenting information. This condition explains the importance of visualized information that can introduce many subjects in the educational environment in an organized manner by applying visual components. In addition, infographics enable multiple designs for the same information to suit different students' preferences. Visual communication by infographics can represent many pages in a simple way and can also reduce explanation effort by employing suitable components of the presented subject, such as graphs, diagrams, images and text in logical sequence.

These properties of the infographic reflect the flexibility to modify visualized information in alternative forms. The second property is the ability to attach multimedia sources with visualized information such as related audios and videos (Yıldırım, 2016).

According to research conducted in Jordanian public universities to find out the problems faced by students in six surveyed domains, the first major problem is instructional methods. The study recommended that a number of educational methods and programs be introduced to enable students to keep up with educational techniques and improve their achievements (Al-khawaldeh \& Alkhrsha, 2015) .So this paper attempts to introduce solution for Jordanian educational methods that serve the education system through evaluate the effect of infographic method considered as 
supported mean for educational purpose . Additionally, upon the experimental findings of this study, the study contributes to the literature on visual communication theory, specifically on the use of infographics for educational aims, and how infographics affects different types of students academically.

\section{ASSURE Instructional Model}

This study adopted ASSURE instructional model as guide for the procedures of infographic experiment. ASSURE model (figure 2.10) developed through Heinich, Russell, Molendo and Smaldino in (1999) as instructional model in order to plan suitable course and technology means to force the education process and gain the most perfect planning. ASSURE acronym has expressed about six steps or procedures: (A) Analyze; which focuses on analyze of the learner's characteristic. (S) State objectives; which means that the tough course should include specific goals, and partly every lesson also the same thing as particular cause. (S) Select media and material; which indicate to the chosen of media and material, Heinich et al (1999) determined two directions for this point: select the method to present instruction, Select the most suitable media for the selected method. Media maybe encompasses multimedia forms (internet resources, DVDs, software, video, visual printout, text) on other words; combination of several media types. (U) Utilize media and material; this step should meet the wanted objectives and aiming to achieve objectives through applying selected material in learning process, (R) Require learner participation; students consider lectures meaningfully when they are active and contributory in lecture. Merge new technology forms with actual learning process will facilitate understanding of acquired knowledge by student, and this is one of most significant priorities of learning system and (E) Evaluate and revise; for perfect view of the outcomes of the technological implementation, permanent evaluation of student performance and learning process, and the best evaluation way is as (Molepo and Mothudi) mentioned: Was the media appropriate , Are there other technological solution may utilize better than that were already used? (Molepo \& Mothudi, 2014).

\section{LITERATURE REVIEWS}

In classrooms, all students learn the same topic although every student may have his/her own preferred learning style. An individual one-on-one meeting with a tutor is the best choice for all students, but this set-up imposes heavy demands on teachers. A possible approach is to add a method that can meet the desired learning style of students. Mark Vondracek (2009) suggested and tested many classroom methods for teaching a subject on 'resistor circuits' to reach the students' maximum level of perception and understanding and meet the students' preferred style. Vondracek's learning model shows that many students prefer visual learning, and they find that the visual material is effective in explaining the taught topic. Furthermore, using a visual representation helps students to observe the links between the concepts and ideas of the taught topic (Vondracek, 2009). Another study has shown the effects of visualized courses on the education process; for example, in Brazil, a study was conducted on 27 undergraduate students, amongst which 14 had chosen to express their opinions on using infographic learning material and 13 had decided to express their opinions on using graphic and text learning material. With the same content in the two cases, the results show 
correspondence between the two cases, but with priority for infographics in the enjoyment and pleasure criteria in the questionnaire test. Another priority observation of students who use infographic material was keeping their acquired information for a longer period than students who used graphic and text, which indicates that infographics can be more effective in reinforcing and supporting the education process(Lyra et al., 2016).

Matrix \& Hodson (2014) reported the utilization of infographic as a participant product in the education process and as an assessment tool to motivate students and create a different learning style that facilitates gaining knowledge, performing communication and recording information.

Thus, when textual material is combined with several visual forms (such as images, graphics, diagrams or charts) in infographic design, the ability to save and retain material information improves, thereby contributing to the educational process. Another case for exploiting visualized material is shown in an experiment by Lapolli (2013) in which visual geometry description is used as a part of the educational material, and then matched with the context to motivate and enhance the ability of deaf students and consider aid technology sets.

Exploiting infographics in education by conveying information or data visually involves the use of tools to interpret and understand complex information by stimulating the student's interest. Using infographics as educational resources enables students to analyze the material contents in a visual way from just reading it, thereby motivating them to begin discussions inside the classroom to make a virtual educational environment. However, infographics should not cancel out or replace academic articles, but are mainly supplementary or complementary learning instruments which encourage the students to effectively learn the course content. This finding was confirmed by Sudakov (2014) who showed that students responded positively to infographic availability at the beginning of a course material in experimental sciences. However, the response was not the same in the social sciences(Guzmán at al, 2015).

Infographics can be merged with the education system to supply acquired knowledge from taught courses. Amy Weiss of San Diego State University examined a massive open online course, which integrated infographics with a course created by the Knight Center for Journalism in the Americas, College of Communications at the University of Texas. This course entitled 'Introduction to Infographic and Data Visualization' was created for journalism students, journalists and anybody interested in learning the subject. The course discussed infographic and data visualization uses, and combined reading subjects, video lectures and tutorials on technical tools with three infographic exercises. After six weeks of the new learning style, a survey was conducted amongst student to obtain feedback. The findings showed that $80 \%$ of 409 learner-participants indicated that they were enthusiastic to learn under the new education system. The participants were also asked to recall the three most important things they had learned; the top lesson mentioned was how to visualize data and infographics, accounting for $46 \%$ of the total. This result indicates the impact of infographics on student during the course period (Liu at al., 2014). 
Yıldırım, Çelik, Yıldırım and Kaban (2016) conducted a study at the Department of Computer and Instructional Technologies Education of Ataturk University. A questionnaire was given to 59 students who stated their opinions about using and reading infographics during the learning process. The study showed that the students considered infographics to have a higher level of informativeness than text and that infographics simplify learning, especially when presenting information in a particular context. Furthermore, the students stated their interest in sharing infographics with peers and friends who may be also interested in infographic technology.

Another result of the study is that the students had higher memory retention of infographics than information in textual form, and that infographics were able to highlight the most critical and important information ( Y1ldırım at al, 2016).

\section{The Provided Abilities of Infographic}

The development of applied graphics is spreading around, and the products of the graphic field can be exploited for numerous purposes; one of these purposes is the educational process by representing information graphically (Vera at al, 2007).

In the current environment with large volumes of data and knowledge from various sources, the accumulated data can be difficult to understand without suitable visual interpreting. Furthermore, visual presentation is able to match science with applied practices between instructors and students. A study (2015) which aimed to develop taught courses in computational science in Russia indicated the weakness of visualization in science, technology, engineering and mathematics (STEM), and the impact of this situation on students' learning outcomes. The study also showed that majority of Russian students had been pressured to obtain a degree in STEM but had no basic knowledge of interpreting visualization principles. Therefore, to address this challenge and solve the problem, 20 Russian universities began to merge visualized course material with general education programs to keep up with global changes in course methods and contents. Furthermore, Karsakov, Bilyatdinova and Bezgodov (2015) presented a modification of two courses to merge them in a new modern syllabus for ITMO University in Saint Petersburg, Russia. The courses had the same academic size but with in-depth knowledge and more visual principles in the classroom (Karsakovat al, 2015).

\section{Interaction by Infographic}

Exploring visual information involves interactive communication between the viewer and the visualized information or infographic. The interaction is considered as the main and core part of represented information, which can be expressed in various graphical forms. Also, by achieving the interactive aspects of infographics, viewers can see and compare several graphical shapes at the same time, which consequently facilitates the acquisition of cognitive knowledge (Dilla, at al,2010). Infographics as a visual form act as an interface or mediator between viewers and a collection of organized data, which used to be complex, inaccessible and difficult to understand. This explains the popular definition of infographic: using computerized support to produce visual shapes, promote interactive communication between individuals and visual representation of abstracts 
and organized data to enhance understanding (Houser, 2014). Nowadays, accelerated technology tool's merits make visual forms desirable for individuals, particularly infographic, as its widespread ongoing to strength rather than weakness, due to the interactive graphic, audio-animation and more forms for infographic tool with multi visual fiction for the viewers (Jabr, 2013). The involved visual form, which aims to achieve any communication (or educational) purpose, includes several sub-units that are integrated to create the whole visual form. These subunits include text, image, diagram, decorative elements and other semiotic units that express a certain meaning to be perceived by the viewer. However, a crucial issue is that the overall visual form may be effective in achieving a certain purpose, while other types cannot serve the wanted purpose(Amare \& Manning, 2007). Thus, determining the appropriate visual form is necessary for infographics to be an effective tool for educational purposes; infographics must apply the principles of design, which refer to choices of color, typography, signs, icons or symbols and design harmony principles such as balance, repetition and correspondence. Furthermore, infographics should have a title and complete story which guarantees that the information is conveyed in a perfect way (Bradshaw \& Porter, 2017).

\section{Perception by Infographic}

In recent decades, writing has become a rarely used manner of representation in taught courses. Other resources have emerged, such as Web and online resources and created productions of teachers; parallel to this variety of resources, images grow increasingly to involve and carry meanings. These changes and movements act as responders for didactic and semiotic explanation. Two indicators of these changes are the use of digital media rather than textbooks and the use of images instead of written text as carrier of meaning for learning representation.

Bezemer and Kress (2008) show in their study the changes and shifts of text, and how visual art experts, designers, writers and editors have considered images, typography, layout designs and semiotic resources as learning targets to create potential for learning. Bezemer and Kress also noted the many opinions or perspectives on the semiotic resources of representation in learning. Some have seen that resources should focus on the comprehension or impact of images on students' mental retention and consideration of taught concepts, whereas others have focused on the way that designers use images in learning representation. Other studies selected electronic media as the scope for learning resources (Kress \& Bezemer, 2008).

A study by Khateeb (2016) examined the insertion of infographics in reusable learning objects (RLO) and traditional didactic lectures (TDL) to develop perception and knowledge about using plastic food containers in microwave ovens. The empirical test compared the effects of infographic intervention in the education process for the mentioned subject and TDL at Clemson University. The pre-score and post-score results of the student samples indicated that increasing the result after using infographics and analyzing the test showed that the right answers with the merged RLO and infographic were more than those of the TDL method. In addition, the study indicated that infographic intervention aided RLO to improve the symbol consideration and health perception on the safe use of plastic food containers. 
Accordingly, infographic has been found as one of the most method to develop and optimize the knowledge on several topics in an effective manner (Khateeb, 2016). Furthermore this ability of infographic let (Houser) to mention a description as infographic is protean in nature Coming in variety forms and pass through multi functions, from learning to gain knowledge, to gain happiness of knowledge perception (Houser, 2014).

\section{Semiotic within Infographic}

Referring to semiotics as the word of sign in any society and to Peirce's term 'semiosis phenomenon,' we can observe the status of the relationship between semiotic shapes and something else needed to be perceived by the viewer, where the sign acquires representative status of something else. When we apply the semiotic theory on educational phenomena, simply we can define the semiotic in education like the study of the life of sign and principle varieties of semiosis inside education. In other words, visual forms are necessary to act on certain educational issues (Anward, 1994). Semiotic signs have been classified by Charles Sanders Peirce; who adopted three main classifications of signs: iconic, index and symbol (Sebeok, 2001).

\section{i. Iconic signs}

The word 'icon' is derived from the Greek work eikon, which refers to an image. It is characterize as the easiest category of interpretation due to a close resemblance to the object represented. Some examples are icons on desktop screens, which represent computer tasks and guide users to specific folders or operation processes (Lester, 2011).

\section{ii. Index signs}

Index refers to an object's location in time or space, or the object's position in relation to another object. If we see a smoke sign for example, we know that it indicates a fire or when we see an electrocardiography sign, we know that it indicates a patient's medical status. However, these signs do not resemble their sources of references; they are indicators and not corresponding visual images; this is the difference between an index and an icon (Sebeok, 2001).

\section{iii. Symbol signs}

Symbols as types of signs that aim to involve information, orientation, definitions and systems and provides alerts or cautions. Symbols are also able to interact with other elements such as colors and typography to represent ideas and messages visually. According to Hamilton (1970), symbols are considered as the practical part of visual communication besides pictures and icons (Awad, 2014). Symbolic representation is an embodiment of an object in which the signifier does not look like the object but a relationship exists between the signifier and object. Symbol is deferent from index sign which afford direct relationship between the object and signifier. Also, symbol is deferent from icon sign, whereas iconic take metaphorical relationship form with represented objects and icon has some resemblance to signified, so this metaphorical relationship facilitates the considering or understanding of relationship. Index somewhere lay between symbolic and iconic whence resemblances to the representative 
object scale (Moere \& Patel, 2010). Almost time it's a fact when it's supposed that experience with symbol improve the level of visual understanding (Walker, Walker \& Ganea, 2012).

\section{METHOD}

In this study, in order to make comparison between two groups; the first group considered as base which was control group and the second group considered as exposed to the infographic tool which was experimental group. Consequently, true experimental approach was applied on two selected courses: Structured Programming Course (SPC) at the Information Technology College and Introduction to Economic Science Course (IESC) at the Economic College. We compared the control groups based on the following considerations: course conducted in the way already used in common instructional methods (textbook, data show, and white board) and the experimental groups based on how the course was conducted using designed instructional courses with infographic techniques utilized in the classroom. Furthermore, both control and experimental groups were used to compare the findings after the experimental test of infographics was applied to certain taught courses (Walliman, 2011).

Infographic materials were involved alongside three chapters for each selected course, split over 16 lectures, which were distributed equally between the two colleges in the second semester of the 2017-2018 academic session.

\section{Participant's Students}

The study participants were first year students in the 2017-2018 academic session. The selection of the first-year level students was justified by including a combination of students from all college departments. Furthermore, the participating students consisted of those with high, medium and low visual literacy about infographic and semiotic sign according to statistic survey that were provided to participants (Table 1). Accordingly, 96 students from the Economic College were selected as a sample distributed over 2 classrooms and 42 students were selected from the Information Technology College as a sample also distributed between 2 classrooms. All participating students had previously been taught the subject using existing methods, which helped in comparing the process between already existing methods and the methods supported by an abundance of visual information through infographics.

The participants were divided into two groups: experimental and control. The experimental group from the Economic College consisted of 38 students, of which the control group consisted of 58 students. The experimental group from the Information Technology College consisted of 20 students, of which the control group consisted of 22 students. 
Table 1

Infographic-Semiotic Signs Students' Background

\begin{tabular}{lllll}
\hline \multicolumn{1}{c}{ Purpose } & \multicolumn{2}{c}{ IT College } & \multicolumn{2}{c}{ Business College } \\
\hline Students' background about & High Knowledge & $10 \%$ & High Knowledge & $8 \%$ \\
infographic concept & Middle Knowledge & $24 \%$ & Middle Knowledge & $33 \%$ \\
& Low Knowledge & $66 \%$ & Low Knowledge & $58 \%$ \\
\hline Students' ability to interpret & High Ability & $76 \%$ & High Ability & $72 \%$ \\
the inference of sign in life & Middle Ability & $20 \%$ & Middle Ability & $21 \%$ \\
& Low Ability & $4 \%$ & Low Ability & $7 \%$ \\
\hline
\end{tabular}

1. The control group through the selected taught subjects utilizing the common methods by which they are usually instructed (textbook, whiteboard).

2. The experimental group through the same subjects but now with the insertion of infographic representation.

The infographic classifications applied to the experimental groups were developed by the researcher. Each classification, such as motion, video and statistics, was applied to students' learning according to the nature of the subject (Siricharoen \& Siricharoen, 2015). To use infographics in instructional design, the researcher needed supervision from the tutors as he was not a specialist in the courses, but needed to gain knowledge to enable the design and development of the infographic medium to be used to support the education process (Gao \& Ming, 2014). The objective of the collaboration between the researcher and tutors was to ensure harmony between the researcher's design of the infographics and the tutors' knowledge of the subjects. Furthermore, the tutors apply the conventional methods in lectures using an authorized textbook for each subject for control groups. The tutors then keep in touch with the students on the same subject and supply them with the developed infographic designs, thereby forming the experimental group.

\section{Data Instruments}

In this study, data collection consisted of the following types:

i. Questionnaire: A survey questionnaire was used in this study to collect quantitative data. Due to the nature of this study, which focuses on the effects of multi-infographic forms and its role in learning process, student's opinions were obtained through a set of questions which included several choices for the respondents, requiring them to select the best answer so that the data would be quantifiable (Walliman, 2011). Copies of the questionnaire were distributed prior to the introduction of infographics, during instructional lectures and after several forms of infographics were used during the lectures. Numerical data collected from the questionnaire aimed to determine the desires and preferences of the students (Creswell, 2009); these preferences referred to the taxonomy of infographic visual forms which lies under motion and non-motion taxonomy. Consequently, two forms of questionnaire consisted of 14 questions were provide to students of experimental groups after infographic experiment to measure interaction and perception of them. The questionnaire was developed through 
cooperation amongst experts in the infographic and visual communication field. Validity and reliability were achieved through investigation and monitoring by visual communication experts.

ii. Quizzes: after each infographic lectures, a short quiz was conducted by the tutors of the taught courses in order to calculate the mean of each student's marks along the three chapters of each experimental group, then these marks were comparing to the short quizzes that were conducted by the tutors of the control group for each college and for the same three selected chapters that have been given in conventional method regard to control groups students.

\section{Developing Infographic for the Selected Chapters}

The first stage was dividing each lecture material into three parts: Introduction and main concepts for the taught course, lesson's content explanation which have abundance in text (more than in introduction/ concepts part) and conclusion for the taught lesson (which have text, but less than lesson's explanation part).

The second stage was dividing the infographic design into multiple graphic presentations by using multi-element designs which change in each lesson depending on student consideration inferences. Changes were applied in the use of graphical elements within the infographics such as colors, sizes and spatial distribution. All of these properties in infographic design can determine the most effective, suitable and efficient infographic design for visual communication between the students and infographic medium. In addition, infographics as one of several visual communication types can involve graphical presentation that reduces the long search process by targeting students in a confined area, as well as grouping several relations of the taught lesson in the same area, consequently helping students to receive, compare and consider the information they need (Casner, 1991).

The third stage was to select the semiotic forms, which were divided into three categories: icon, index and symbol, either in single form in each choice or by creating a mutual link between the three categories of sign that can be exploited to represent the overall idea for a specific topic, issue or subject (Uggla, 2006), according to the main target that each sign category aims to reach. Figure 1 displays the level of resemblance amongst index, icon and symbol, as well as shows the intents and meaning of the three categories, a basic idea that was considered in designing infographics for the taught lessons. 


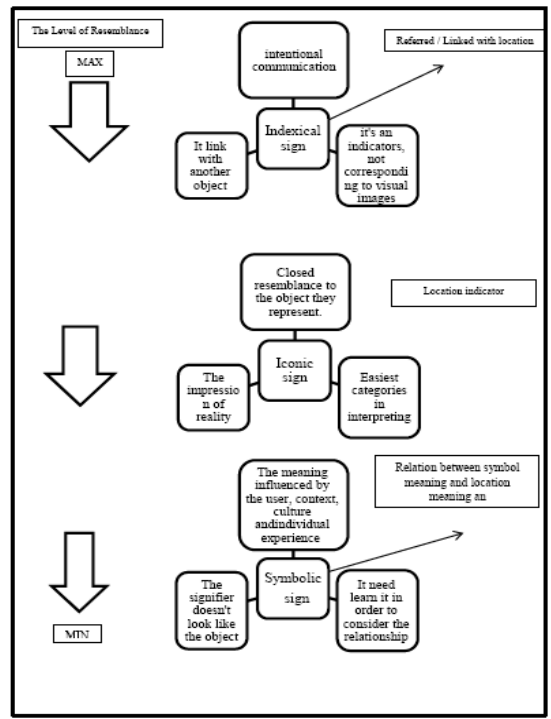

Figure 1

Infographic Resemblance Levels

\section{Presenting Infographic for the Selected Chapters}

In each lecture the following procedures were executed for the three selected chapters from the two courses; User-Defined Functions (1), User-Defined Functions (2), Functions with Default Parameters, the chapters regarding to (SPC) course/ Information Technology College, which acts the scientific colleges, whereas Equilibrium, Inflation and Unemployment, Monitory and Fiscal Policies chapters regarding to (IES) course/ Economic and Administrative Science College which acts the humanistic colleges.

- The Experimental Group

1. Tutor presentation: tutor reviewed the main titles of the taught lesson and the lecture arrangement process.

2. Infographic presentation:

$\checkmark$ Introduction: infographic video presented the concepts, definition and the core points as preliminary entrance to the taught lesson.

$\checkmark$ Content: several infographic designs and semiotic selections were presented in the content explanation of the taught lesson at duration longer than introduction duration.

$\checkmark$ Conclusion: infographic video reviewed the concluded points that summarize the entire taught lesson. 
3. Post-test: After the lesson, the tutor administered a short quiz, which included predetermined questions for the students to answer. The quiz papers were collected after seven minutes. The tutor evaluated and marked the answer sheets.

\section{- The Control Group}

Tutor presentation: The tutors explained the lesson in the conventional method they actually use during lectures, that is, by using a textbook, a whiteboard and other tools.

2. Post-test: In parallel to the experimental group, the tutor administered a short quiz about the lesson. Other quizzes were conducted after the end of each lesson. The duration of each quiz was also seven minutes, as implemented in the experimental group. The answer sheets were collected, evaluated and marked by the tutors.

\section{FINDINGS AND DISCUSSION}

\section{Mean of the Quizzes}

To measure the effect of infographics on experimental groups for each college, a set of quizzes on a 10-point scale was used for all students in the experimental and control groups after presenting infographic lectures in the experimental groups. After the infographic experiment was finished, the findings indicated that the mean of marks in the experimental group from the IT College was (7.9/10), which was higher than that of the control group at (6.6/10). The mean of marks in the experimental group from the Business College was (7.5/10), which was also higher than the mean of marks of the control group at (5.7/10). These results were indicators for the effect of infographics on students and the students' interaction and perception in particular.

\section{Questionnaires Findings}

In this study, a set of two questionnaires was given to students after conducting an infographic experiment in the second semester of academic year 2017-2018. The questionnaires, which used a five-point Likert scale, were given to participants after the infographic experiment to measure the effect of instructional infographic material on two variables. The variables were; students' interaction during the lectures and students' perception of the given information.

\section{Principal Component Analysis}

A principal component was conducted on collected data to determine the importance and correlation of the sub-variables that measure each main variable.

\section{Students interaction}

The findings of PCA for the interaction variable regard to Information Technology College shows that the seven sub-variables can be divided into two components based on each sub-variable variance explained to the total variance explained. The first component explained $46.568 \%$ of the total variance and the second component explained $19.487 \%$ of the total variance. Table 2 shows the seven sub-interaction variables distributed; the importance in the interaction variable is divided into two variables. 
Table 2

Principal Component Findings of Students Interaction-Information Technology College

\begin{tabular}{lll}
\hline The Sub- Variable & \multicolumn{2}{l}{ Component } \\
\cline { 2 - 3 } & 1 & 2 \\
\hline $\begin{array}{l}\text { The role of infographics in motivating student's participation during given } \\
\text { lectures. }\end{array}$ & .900 & - \\
\hline The role of repeated mono design in a particular subject. & $-.829-$ & - \\
\hline $\begin{array}{l}\text { The role of applying multi-infographic design forms in making students active } \\
\text { and energetic. }\end{array}$ & .812 & - \\
\hline The role of the clarity level of semiotic signs used in infographic material. & $-.770-$ & - \\
\hline $\begin{array}{l}\text { The role of visual shape within the infographic materials in motivating students to } \\
\text { ask questions. }\end{array}$ & .664 & - \\
\hline The effect of infographics on the student-tutor discussion level. & - & .840 \\
\hline The effect of infographics on the student-textbook relationship. & - & .518 \\
\hline Extraction Method: Principal Component Analysis. a. 2 components extracted & \\
\hline
\end{tabular}

PCA for the interaction variables regard to Business College shows that the seven subvariables can be divided into two components based on each sub-variable variance explained to total variance explained. The first component explained $47.130 \%$ of the total variance and the second component explained $16.812 \%$ of the total variance. PCA yields two components from the seven sub-variables (Table 3).

Table 3

Principal Component Findings of Students Interaction-Business College's Students

\begin{tabular}{lll}
\hline The Sub- Variable & Component \\
\cline { 2 - 3 } & 1 & 2 \\
\hline The role of infographics in motivating student's participation during given & .844 & - \\
lectures. & .789 & - \\
\hline $\begin{array}{l}\text { The role of applying multi-infographic design forms in making students active } \\
\text { and energetic. }\end{array}$ & -742 & - \\
\hline $\begin{array}{l}\text { The role of visual shape within the infographic materials in motivating students to } \\
\text { ask questions. }\end{array}$ & \\
\hline The role of repeated mono design in a particular subject. & $-.727-$ & - \\
\hline The role of the clarity level of semiotic signs used in infographic material. & $-.603-$ & - \\
\hline The effect of infographics on the student-tutor discussion level. & $-.530-$ & - \\
\hline The effect of infographics on the student-textbook relationship. & -628 \\
\hline Extraction Method: Principal Component Analysis. a. 2 components extracted & \\
\hline
\end{tabular}

\section{Students perception}

The principal component of the second main variables regard to Information Technology College shows that the seven sub-variables are divided into two components based on each sub-variable variance explained to total variance explained. The first component explained $57.842 \%$ of the total variance. The second component explained $14.828 \%$ of the total variance. In the perception main variable, two components were yielded by PCA. The 7 sub-variables were distributed into two components as in (Table 4). 
Table 4

Principal Component Findings of Students Perception-Information Technology College

\begin{tabular}{lll}
\hline The Sub- Variable & \multicolumn{2}{l}{ Component } \\
\cline { 2 - 3 } & 1 & 2 \\
\hline $\begin{array}{l}\text { The level of difficulties as regards students' explanation of semiotic signs } \\
\text { within the infographics. }\end{array}$ & $-.846-$ & - \\
\hline $\begin{array}{l}\text { How students were able to obtain the meaning of semiotic signs within } \\
\text { the infographic material easily. }\end{array}$ & .845 & - \\
\hline $\begin{array}{l}\text { How the semiotic signs within the infographic material carried and } \\
\text { indicated the wanted meaning of the given information. }\end{array}$ & $-.810-$ & - \\
\hline $\begin{array}{l}\text { How the semiotic signs within the infographic material brought the given } \\
\text { information closer to students. }\end{array}$ & .754 & - \\
\hline $\begin{array}{l}\text { The role of infographics in involving enjoyment and integrating it with } \\
\text { knowledge acquisition. }\end{array}$ & .713 & - \\
\hline $\begin{array}{l}\text { The role of infographics in developing a student's level of transported } \\
\text { information understanding. }\end{array}$ & .691 & - \\
\hline $\begin{array}{l}\text { How the semiotic signs within infographic materials make information } \\
\text { perception complicated and confounding. }\end{array}$ & - & .663 \\
\hline Extraction Method: Principal Component Analysis. a. 2 components extracted
\end{tabular}
Extraction Method: Principal Component Analysis. a. 2 components extracted

Also, regard to Business College main variable, perception variable, three components resulted from PCA and the seven sub-variables distributed in them. The first component explained $44.528 \%$ of the total variance, the second explained $17.367 \%$ and the third explained $14.984 \%$. The seven sub-variables were distributed and sorted on the three components in descending order of importance of each sub-variable in each component, as in (Table 5).

Table 5

Principal Component Findings of Students Perception-Business College

\begin{tabular}{|c|c|c|c|}
\hline \multirow{2}{*}{ The Sub- Variable } & \multicolumn{3}{|c|}{ Component } \\
\hline & 1 & 2 & \\
\hline $\begin{array}{l}\text { How the semiotic signs within the infographic materials brought the } \\
\text { given information closer to students. }\end{array}$ & .824 & - & - \\
\hline $\begin{array}{l}\text { The level of difficulties as regards student explanation of semiotic } \\
\text { signs within the infographics. }\end{array}$ & $.763-$ & - & - \\
\hline $\begin{array}{l}\text { The extent to which the semiotic signs within the infographic } \\
\text { material carried and indicated the wanted meaning of the given } \\
\text { information. }\end{array}$ & $\begin{array}{l}- \\
.742-\end{array}$ & - & - \\
\hline $\begin{array}{l}\text { The role of infographics in developing students' levels of } \\
\text { transported information understanding. }\end{array}$ & .709 & - & - \\
\hline $\begin{array}{l}\text { How the students were able to obtain the meaning of semiotic signs } \\
\text { within the infographic material easily. }\end{array}$ & .613 & - & - \\
\hline $\begin{array}{l}\text { The role of infographics in involving enjoyment and integrating it } \\
\text { with knowledge acquisition. }\end{array}$ & - & .7843 & - \\
\hline $\begin{array}{l}\text { How the semiotic signs within infographic materials make } \\
\text { information perception complicated and confounding. }\end{array}$ & - & - & .605 \\
\hline
\end{tabular}




\section{Regression Analysis}

Regression Analysis was conducted to determine if there was a significant effect of infographic on students' interaction and perception.

\section{Infographic impact on students' interaction}

Regression analysis was conducted to determine the relationships between two or more variables. Consequently, a simple regression has two variables, namely, independent and dependent (Kothari, 2004). Here, the independent variable was the mean of quiz marks $(\mathrm{MM})$ of the students after applying the infographic experiment on the two experimental groups (MM). The mean of quiz marks (MM) considered as measurement of the effect of infographic; therefore, MM act infographic. Furthermore, the dependent variable was the mean of questionnaire responses on interaction (MI) and perception (MP) in two analysis processes separately with one independent variable, the mean of quiz marks (MM).

Null hypothesis $\rightarrow$ H0: there no significant relationship between the independent variable; infographic (MM) variable and the two dependent variables interaction and perception (MI, MP) severally.

Alternative hypothesis $\rightarrow \mathrm{H} 1$ : there is significant relationship between the independent variable; infographic (MM) variable and the four dependent variables interaction and perception (MI, MP) severally (Sekaran, 2003). In addition, the level of significant is important to accept or reject $\mathrm{H} 0$ hypothesis, so if the significant value $=<.05$, then the HO will reject, in other significant value possibilities; H0 will accept (Kothari, 2004).

A regression analysis finding of Information Technology College as in Table 6 shows that the level of significance is 0.00 , which is less than 0.05 when the value of $F$ is 55.867. Therefore, HO can be rejected. Thus, using infographics by instructional lecture has a significant impact on the interaction of students. In addition, Table 6 shows the value of $\mathrm{R}$-square change that reaches 0.756 . Thus, the independent variable (MM) explains $75.6 \%$ of the dependent variable (MI.IT).

Also, regression analysis of the interaction variable regard to Business College (Table 6) shows the level of significance at 0.00 , which is less than 0.05 when the value of $F$ is 85.195. Thus, HO can be rejected, which means that a significant impact exists when using infographics in instructional lectures on the interaction of students during lectures. In Table 6 , the value of $\mathrm{R}$-square change reached 0.703 . Thus, the independent variable (MM) explains $70.3 \%$ of the dependent variable (MI.ECO).

Table 6

Model Summary of Mean of marks $\rightarrow$ Interaction

\begin{tabular}{|c|c|c|c|c|c|c|c|c|}
\hline \multirow[b]{4}{*}{ College } & \multirow[b]{4}{*}{$\mathrm{R}$} & \multirow[b]{4}{*}{ R Square } & \multicolumn{6}{|c|}{ Change Statistics } \\
\hline & & & & Std. Error & $\overline{\mathrm{R}}$ & & & \\
\hline & & & Adjusted R & of the & Square & $\mathrm{F}$ & & Sig. F \\
\hline & & & Square & Estimate & Change & Change df1 & df 2 & Change \\
\hline$\overline{\mathrm{IT}}$ & $.870^{\mathrm{a}}$ & .756 & .743 & .32909 & .756 & $\begin{array}{ll}55.867 & 1\end{array}$ & 18 & .000 \\
\hline Business & $.838^{\mathrm{a}}$ & .703 & .695 & .37046 & .703 & 85.1951 & 36 & .000 \\
\hline
\end{tabular}




\section{Infographic impact on students' perception}

In Table 7, for perception regression of Information Technology College, the significance level is 0.00 , which is less than 0.05 when $\mathrm{F}$ value is 204.273 . Thus, $\mathrm{H} 0$ can be rejected, which means that significant effects exist when using infographic in instructional lectures on receiving and perception knowledge by students. And the value of R-square change reached 0.919. Thus, the independent variable (MM) explains $91.9 \%$ of the dependent variable (MP.IT).

Regression analysis as regards perception variable of Business College (Table 7) shows the level of significance at 0.03 , which is less than 0.05 when the value of $F$ is 85.195. In this case, $\mathrm{H} 0$ is rejected. Thus, a significant impact exists when using infographics in instructional lectures on receiving and perception knowledge by students. And the value of R-square change reached 0.919. Thus, the independent variable (MM) explains $91.9 \%$ of the dependent variable (MP.ECO).

Table 7

Model Summary of Mean of Marks $\rightarrow$ Perception

\begin{tabular}{|c|c|c|c|c|c|c|c|c|c|}
\hline \multirow[b]{2}{*}{ College } & \multirow[b]{2}{*}{$\mathrm{R}$} & \multirow[b]{2}{*}{ R Square } & \multicolumn{7}{|c|}{ Change Statistics } \\
\hline & & & $\begin{array}{l}\text { Adjusted R } \\
\text { Square }\end{array}$ & $\begin{array}{l}\text { Std. Error } \\
\text { of the } \\
\text { Estimate }\end{array}$ & $\begin{array}{l}\mathrm{R} \\
\text { Square } \\
\text { Change }\end{array}$ & $\begin{array}{l}\text { F } \\
\text { Change }\end{array}$ & df1 & df2 & $\begin{array}{l}\text { Sig. F } \\
\text { Change }\end{array}$ \\
\hline$\overline{\mathrm{IT}}$ & $.959^{\mathrm{a}}$ & .919 & .915 & .24670 & .919 & 204.273 & 1 & 18 & .000 \\
\hline Business & $.476^{\mathrm{a}}$ & .226 & .205 & .57063 & .226 & 10.541 & 1 & 36 & .003 \\
\hline
\end{tabular}

\section{Kruskal-Wallis Test}

\section{IT \& Business Infographic impact comparison}

In order to examine the following hypothesis, Kruskal-Wallis test was conducted on data of two colleges' samples.

\section{Null hypothesis $\rightarrow$ H0: MIT $=$ MECO}

This hypothesis indicates that there is deference of infographic impact occurs on each of four variables between samples of scientific humanistic and college.

Alternative hypothesis $\rightarrow \mathrm{H} 1:$ MIT $\neq$ MECO

This hypothesis indicates that there is deference of infographic impact occurs on each of four variables between samples of scientific humanistic and college(Kothari, 2004).

Table 8 shows that the Kruskal-Wallis test uses a chi-square table as a reference to approximate the calculated $\mathrm{H}$ (Shanafelt et al., 2015). As regards the interaction test, the calculated $\mathrm{H}$ was 5.819 . Consequently, it was more than the approximated chi-square value at 0.05 significance level and 1 degree of freedom, which is 3.841(Kothari, 2004). As a result, the null hypothesis was rejected. Thus, a difference was observed between 
the scientific college sample (IT students) and humanistic college sample (ECO students) as regards the impact of instructional infographics on their interaction within the classroom.

On other hand, information perception of students, was examined by Kruskal-Wallis test to determine the existence of a different impact of instructional infographics between the scientific college sample (IT students) and humanistic college sample (ECO students) as shown in (Table 8). The results in Table 4.36 show the calculated $\mathrm{H}$ of the perception variable, which was 0.01 . In the chi-square table, the approximated value at 0.05 significance level and 1 degree of freedom is 3.841 . Accordingly, the calculated $\mathrm{H}$ was less than this value.

The null hypothesis was accepted referring to the statistical results of the KruskalWallis test, which means that no difference occurred between the scientific college sample (IT students) and humanistic college sample (ECO students) as regards the impact of instructional infographics on their information perception

Table 8 Interaction and Perception Kruskal- Wallis Test Statistics ${ }^{\mathrm{a}, \mathrm{b}}$

\begin{tabular}{lll}
\hline & Interaction & \multicolumn{1}{c}{$\begin{array}{c}\text { Perception } \\
\text {.IT.ECO }\end{array}$} \\
\hline Chi-Square & .IT.ECO & .001 \\
df & 5.819 & 1 \\
Asymp. Sig. & 1 & .980 \\
\hline a. Kruskal Wallis Test b. Grouping Variable: No.Group & .016 & \\
\hline
\end{tabular}

\section{CONCLUSION}

This experimental study was conducted on two deferent student academic field; scientific and humanistic colleges in order to examine the effect of infographic on their interaction within classroom and their perception of the provided information via infographic. As shown in findings of this study; infographic have positive effect on both college's samples; Information Technology college and Business College. Also this positive fact have been proved by comparing the quizzes marks of students along experimental and control groups for each colleges which indicated to superiority of experimental groups on control groups in each college.

The findings of this study show close corresponding of infographic effect on Information Technology College and Business College where the ability of infographics to support students' perception of the provided information. This similarity is interpreted by the characteristic of the infographic as visual communication form which has the ability to deliver the intended meaning of information visually and assists the student to perceive the information by the carrier of information which is the semiotic signs that link by a paired summarized text to transmit visual information.

On the other hand, an infographic has a different effect between the two colleges whence the interaction within the classroom and with their tutor and colleagues, and that interpreted by students perspective to infographic contents which include several 
semiotic categories and graphical designs which depend on aesthetic thoughts of students themselves which actually defers from one person to another.

\section{REFERENCES}

Al-khawaldeh, S. S., \& Alkhrsha, S. F. (2015). Problems of Jordanian public universities' students: A survey study. International Journal of Education, 7(4), 120137. https://doi.org/10.5296/ije.v7i4.7779.

Amare, N., \& Manning, A. (2007). The language of visuals: Text + graphics = visual rhetoric. IEEE Transactions on Professional Communication, 50(1), 57-70. https://doi.org/10.1109/TPC.2006.890851.

Anward, J. (1994). Semiotics in educational research. International Encyclopedia of Educational Research, 9, 5411-5417.

Awad, E. T. A. (2014). Identification of competencies for sign designers in Jordan Identification of Competencies for Sign Designers in Jordan (Unpublished doctoral dissertation). Coventry University, UK.

Babu, A. R. (2015). Comparative analysis of cascadeded multilevel inverter for phase disposition and phase shift carrier PWM for different load. Indian Journal of Science and Technology, 8(April), 251-262. https://doi.org/10.17485/ijst/2015/v8iS7/.

Bradshaw, M. J., \& Porter, S. (2017). Infographics a new tool for the nursing classroom. Nurse Educator, 42(2), 57-59. https://doi.org/10.1097/NNE.0000000000000316.

Casner, S. M. (1991). A task-analytic approach to the automated design of graphic presentations. ACM Transactions on Graphics, 10, 111-151..

Creswell, J. W. (2009). Research design qualitative, quantitative, and mixed methods approaches. London: SAGE Publications.

Dilla, W., Janvrin, D. J., \& Raschke, R. (2010). Interactive data visualization: New Directions for accounting information systems research. Journal of Information Systems, 24(2), 1-37. https://doi.org/10.2308/jis.2010.24.2.1.

Gao, R., \& Ming, Y. Z. (2014). Infographics applied in design education. In 2014 IEEE Workshop on Advanced Research and Technology in Industry Applications (WARTIA) (pp. 984-986). Ottawa: IEEE.

Guzmán-Cedillo, Y. I., Lima-Villeda, N., \& Ferreira-Rosa, S. (2015). An experience of elaborating didactic infographics on sexual diversity. Revista Latina de Comunicación Social, (70), 961-981. https://doi.org/http://dx.doi.org/10.4185/RLCS-2015-1080en.

Houser, H. (2014). The aesthetics of environmental visualizations: more than information ecstasy? Public Culture, 26(2), 319-337. https://doi.org/10.1215/089923632392084.

Jabr, F. (April, 2013). The Reading brain in the digital age: The science of paper versus screens. Scientific American. Retrieved from 
http://www.scientificamerican.com/article/reading-paper-screens/

Karsakov, A., Bilyatdinova, A., \& Bezgodov, A. (2015). Improving visualization courses in russian higher education in computational science and high performance $\begin{array}{lllll}\text { computing. Procedia } & \text { Computer } & \text { Science, } & 66, & \end{array}$ https://doi.org/10.1016/j.procs.2015.11.083.

Khateeb, N. A. (2016). Examination of infographics-based reusable learning objects $(R L O)$ and traditional didactic lectures (TDL) to improve consumer knowledge and perceptions about the safe use of plastic food containers in a microwave oven (unpublished doctoral dissertation). Clemson University, USA.

Kothari, C. R. (2004). Research methodology: Methods and techniques. New Delhi: New Age International.

Kress, G., \& Bezemer, J. (2008). 1. writing in multimodal texts: A social semiotic account of designs for learning. Written Communication, 25(2), 166-195. https://doi.org/10.1177/0741088307313177.

Lester, P. M. (2011). Visual communication: Images with messages. Belmont, CA: Thomson Wadsworth.

Lin, J., Newman, M. W., Hong, J. I., \& Landay, J. a. (2000). DENIM: Finding a tighter fit between tools and practice for web site design. Proceedings of the SIGCHI Conference on Human Factors in Computing Systems (CHI'00), 2(1), 1-6. https://doi.org/http://doi.acm.org/10.1145/332040.332486.

Liu, M., Kang, J., Cao, M., Lim, M., Ko, Y., Myers, R., \& Schmitz Weiss, A. (2014). Understanding MOOCs as an emerging online learning tool: Perspectives from the students. American Journal of Distance Education, 28(3), 147-159. https://doi.org/10.1080/08923647.2014.926145.

Lyra, K. T., Isotani, S., Reis, R. C. D., Marques, L. B., Pedro, L. Z., Jaques, P. A., \& Bitencourt, I. I. (2016). Infographics or graphics+text: Which material is best for robust learning? In Proceedings - IEEE 16th International Conference on Advanced Learning Technologies, ICALT 2016 (pp. 1-5). Austin: IEEE. https://doi.org/10.1109/ICALT.2016.83.

Moere, A. Vande, \& Patel, S. (2010). The physical visualization of information: Designing data sculptures in an educational context. In M. Huang, Q. Nguyen, \& K. Zhang (Eds.), Visual information communication (pp. 1-23). Boston, MA: Springer. https://doi.org/10.1007/978-1-4419-0312-9_1.

Molepo, L., \& Mothudi, H. (2014). Factors that hinder students benefitting from videoconference broadcast services. Mediterranean Journal of Social Sciences, 5(1), 497-506. https://doi.org/10.5901/mjss.2014.v5n1p497.

Sebeok, T. A. (2001). Signs: An introduction to semiotics. Toronto: University of Toronto Press. 
Sekaran, U. (2003). Research methods for business: A skill buliding approach. USA: John Wiley \& Sons.

Shanafelt, T. D., Hasan, O., Dyrbye, L. N., Sinsky, C., Satele, D., Sloan, J., \& West, C. P. (2015). Changes in burnout and satisfaction with work-life balance in physicians and the general US working population between 2011 and 2014. MAYO Clinic Proceedings, 90(12), 1600-1613. https://doi.org/10.1016/j.mayocp.2015.08.023.

Siricharoen, W. V., \& Siricharoen, N. (2015). How infographic should be evaluated? In The 7th International Conference on Information Technology, (pp.558-564). Amman:ICIT. https://doi.org/10.15849/icit.2015.0100.

Smiciklas, M. (2012). The power of infographics: Using pictures to communicate and connect with your audience. Indiana: QUE.

Uggla, H. (2006). The corporate brand association base: A conceptual model for the creation of inclusive brand architecture. European Journal of Marketing, 40(7/8), 785802. https://doi.org/10.1108/03090560610669991.

Vera, L., Campos, R., Herrera, G., \& Romero, C. (2007). Computer graphics applications in the education process of people with learning difficulties. Computers and Graphics (Pergamon), 31(4), 649-658. https://doi.org/10.1016/j.cag.2007.03.003.

Vondracek, M. (2009). Teaching with multiple methods in mind. Science Teacher, 76(3), 38-41.

Walliman, N. (2011). Research methods the basics. London \& New Yourk: Routledge.

Walker, C., Walker, L., \& Ganea, P. A. (2012). The role of symbol-based experience in early learning and transfer from pictures: Evidence from Tanzania. Developmental Psychology, 49(7), 1315-1324. .

Yıldırım, S. (2016). Infographics for educational purposes: Their structure, properties and reader approaches. Turkish Online Journal of Educational Technology, 15(3), 98110 .

Yıldırım, S., Çelik, E., Yıldırım, G., \& Kaban, A. (2016). A study on the development of an infographic reader questionnaire and reader opinions. Paper presented at the SHS Web of Conferences. Sarajevo. 